Pacific Journal of Mathematic 


\title{
GENERALIZATIONS OF THE ROBERTSON FUNCTIONS
}

\author{
EDWARD J. Moulis, JR.
}

We study a class of analytic functions which unifies a number of classes previously studied, including functions with boundary rotation at most $k \pi$, functions convex of order $\rho$ and the Robertson functions, i.e., functions $f$ for which $z f^{\prime}$ is $\alpha$-spirallike. We obtain representation theorems for this general class, and using a simple variational formula, also obtain sharp bounds on the modulus of the second coefficient of the series expansion of these functions. Using a univalence criterion due to Ahlfors, we determine a condition on the parameters $k, \alpha$, and $\rho$ which will ensure that a function in this class is univalent. This result improves previously published results for various subclasses and is sharp for the class of functions $f$ for which $z f^{\prime}$ is $\alpha$-spirallike of order $\rho$.

1. Let $P_{\alpha}^{k}(\rho)$ denote the class of regular functions $p(z)$ in $E=$ $\{z:|z|<1\}$ such that $p(0)=1$ and

$$
\int_{0}^{2 \pi}\left|\frac{\operatorname{Re}\left\{e^{i \alpha} p(z)-\rho \cos \alpha\right\}}{1-\rho}\right| d \theta \leqq k \pi \cos \alpha,
$$

$k \geqq 2,0 \leqq \rho<1, \alpha$ real, $|\alpha|<\pi / 2, z=\mathrm{re}^{i \theta}, 0 \leqq r<1$.

Let $V_{\alpha}^{k}(\rho)$ denote the class of functions regular in $E$ with $f(0)=f^{\prime}(0)-1=0$ and

$$
1+\frac{z f^{\prime \prime}(z)}{f^{\prime}(z)} \in P_{\alpha}^{k}(\rho)
$$

$k, \alpha$, and $\rho$ as above. $V_{0}^{k}(0)$ is the class of functions with bounded boundary rotation. $V_{\alpha}^{k}(0)$ is a generalization of this class which has been studied recently ([7] and [13]). Padmanabhan and Parvatham [9] have studied properties of $V_{0}^{k}(\rho)$. In this paper we study properties of $V_{\alpha}^{k}(\rho)$ which unlike $V_{0}^{k}(\rho)$ contains functions whose boundary rotation is not necessarily bounded. A function $f$ belongs to $V_{\alpha}^{2}(\rho)$ if and only if

$$
\operatorname{Re}\left\{e^{i \alpha}\left[\frac{1+z f^{\prime \prime}(z)}{f^{\prime}(z)}\right]\right\}>\rho \cos \alpha
$$

$\rho$ and $\alpha$ as above. When $\rho=0$, we obtain the class of functions $f(z)$ for which $z f^{\prime}(z)$ is $\alpha$-spirallike, which has been studied by M.S. Robertson [10], Libera and Ziegler [6], Bajpai and Mehrok [2], and Kulshrestha [5]. The case when $k=2$ but $\rho$ and $\alpha$ are not zero has been studied by Chichra [4] who denoted the class $F_{\alpha}^{\rho}$. This 
class also has been studied by Sizuk [12], who has called $z f^{\prime}(z) \alpha$ spiral-shaped of order $\rho$. The class $V_{0}^{2}(\rho)$ is the class of functions which are convex of order $\rho$, introduced by M. S. Robertson in 1936.

LeMma 1. If $p(z) \in P_{\alpha}^{k}(\rho)$, then

$$
e^{i \alpha} p(z)=\frac{\cos \alpha}{2 \pi} \int_{0}^{2 \pi} \frac{1+(1-2 \rho) z e^{i \theta}}{2-z e^{i \theta}} d \psi(\theta)+i \sin \alpha,
$$

where $\psi(\theta)$ is a function with bounded variation in $[0,2 \pi]$ satisfying

$$
\int_{0}^{2 \pi} d \psi(\theta)=2 \pi \text { and } \int_{0}^{2 \pi}|d \psi(\theta)| \leqq k \pi
$$

Proof. Let

$$
g(z)=\frac{e^{i \alpha} p(z)-\rho \cos \alpha-i \sin \alpha}{(1-\rho) \cos \alpha},
$$

and let

$$
u(z)=\operatorname{Re}\{g(z)\}=\operatorname{Re}\left\{\frac{\rho(z)-\rho \cos \alpha}{(1-\rho) \cos \alpha}\right\} .
$$

Then since $p(z) \in P_{\alpha}^{k}(\rho), \int_{0}^{2 \pi}\left|u\left(\mathrm{re}^{i \theta}\right)\right| d \theta \leqq k \pi$, and according to a representation theorem due to Paatero [8],

$$
\frac{e^{i \alpha} p(z)-\rho \cos \alpha-i \sin \alpha}{(1-\rho) \cos \alpha}=\frac{1}{2 \pi} \int_{0}^{2 \pi} \frac{1+z e^{i \theta}}{1-z e^{i \theta}} d \psi(\theta),
$$

where $\psi(\theta)$ has bounded variation and satisfies condition (1.2) above. The conclusion of the lemma follows.

Now let $f(z) \in V_{\alpha}^{k}(\rho)$. By a theorem due to Padmanabhan and Parvatham [9], the integral in (1.1)

$$
\frac{1}{2 \pi} \int_{0}^{2 \pi} \frac{1+(1-2 \rho) z e^{i \theta}}{1-z e^{i \theta}} d \psi(\theta)=1+z f_{0}^{\prime \prime}(z) / f_{0}^{\prime}(z),
$$

for some $f_{0}$ in $V_{0}^{k}(\rho)$. So

$$
\begin{gathered}
e^{i \alpha}\left[1+\frac{z f^{\prime \prime}(z)}{f^{\prime}(z)}\right]=\cos \alpha\left[1+\frac{z f_{0}^{\prime \prime}(z)}{f_{0}^{\prime}(z)}\right]+i \sin \alpha . \\
\frac{f^{\prime \prime}(z)}{f^{\prime}(z)}=e^{i \alpha} \cos \alpha\left[\frac{1}{z}+\frac{f_{0}^{\prime \prime}(z)}{f_{0}^{\prime}(z)}\right]+i \frac{e^{-i \alpha} \sin \alpha-1}{z} .
\end{gathered}
$$

Integrating, we obtain 
LEMma 2. $f(z)$ is in $V_{\alpha}^{k}(\rho)$ if and only if there is a function $f_{0}(z)$ in $V_{0}^{k}(\rho)$ such that

$$
f^{\prime}(z)=\left[f_{0}^{\prime}(z)\right]^{e^{-i \alpha} \cos \alpha}
$$

The function $f_{0}(z)$ in $V_{0}^{k}(\rho)$ has associated with it a function $g_{0}(z)$ in $V_{0}^{k}(0)$. ([9], Lemma 2.)

LEMMA 3. $f(z)$ is in $V_{\alpha}^{k}(\rho)$ if and only if there is a function $g_{0}(z)$ in $V_{0}^{k}(0)$ such that

$$
f^{\prime}(z)=\left[g_{0}^{\prime}(z)\right]^{(1-\rho) e^{-i \alpha} \cos \alpha} .
$$

Lemma 4. $f(z)$ is in $V_{\alpha}^{k}(\rho)$ if and only if there exists a function $g(z)$ in $V_{\alpha}^{k}(0)$ such that

$$
f^{\prime}(z)=\left[g^{\prime}(z)\right]^{(1-\rho)} .
$$

Proof. The function $\left[g_{0}^{\prime}(z)\right]^{-i \alpha \cos \alpha}$ determines a function $g_{\alpha}^{\prime}(z)$, where $g_{\alpha}(z)$ is in $V_{\alpha}^{k}(0)$ [7].

From Paatero's representation theorem for functions with bounded variation [8], we obtain the following representation.

THEOREM 1. $f(z)$ is in $V_{\alpha}^{k}(\rho)$ if and only if there exists a function $\psi(\theta)$ with bounded variation on $[0,2 \pi]$ satisfying condition (1.2) and

$$
f^{\prime}(z)=\exp \left\{\frac{-(1-\rho) e^{-i \alpha} \cos \alpha}{\pi} \int_{0}^{2 \pi} \log \left(1-z e^{i \theta}\right) d \psi^{\prime}(\theta)\right\}
$$

THEOREM 2. $f(z)$ is in $V_{\alpha}^{k}(\rho)$ if and only if

(A) there exist starlike functions $S_{1}, S_{2}$ such that

$$
f^{\prime}(z)=\left\{\left[\frac{\left[\frac{S_{1}(z)}{z}\right]^{(k+2) / 4}}{\left[\frac{S_{2}(z)}{z}\right]^{(k-2) / 4}}\right\}^{(1-\rho) e^{-i \alpha} \cos \alpha}\right.
$$

(B) there exist $\alpha$-spiral functions $T_{1}, T_{2}$ such that

$$
f^{\prime}(z)=\left\{\left[\frac{T_{1}(z)}{z}\right]^{(k+2) / 4}\right\}^{1-\rho}
$$

(C) there exist functions $L_{1}, L_{2}$ in $V_{0}^{2}(0)$ such that 


$$
f^{\prime}(z)=\left\{\frac{\left[L_{1}^{\prime}(z)\right]^{(k+2) / 4}}{\left[L_{2}^{\prime}(z)\right]^{(k-2) / 4}}\right\}^{(1-\rho) e^{-i(\alpha} \cos \alpha} .
$$

(D) there exist functions $H_{1}, H_{2}$ in $V_{0}^{2}(\rho)$ such that

$$
f^{\prime}(z)=\left\{\frac{\left[H_{1}^{\prime}(z)\right]^{(k+2) / 4}}{\left[H_{2}^{\prime}(z)\right]^{(k-2) / 4}}\right\}^{e^{-i(x} \cos \alpha} .
$$

Proof. (A) follows from Lemma 3 and Brannan's representation for functions with bounded boundary rotation [3]. (B) follows from (A) since $s(z)$ is starlike if and only if $T(z)=z[s(z) / z]^{e^{-i \alpha} \cos \alpha}$ is $\alpha$ spirallike. (C) follows from (A) because of the fact that $H(z)$ is convex if and only if $z H^{\prime}(z)=S(z)$ is starlike. (D) follows trivially from (C).

2. Properties of functions in $V_{\alpha}^{k}(\rho)$.

COROLlary 1. Suppose $f(z)=z+a_{2} z^{2}+\cdots$ is in $V_{\alpha}^{k}(\rho)$. Then $\left|a_{2}\right| \leqq k(1-\rho) \cos \alpha / 2$, and this bound is sharp.

Proof. It is well known that if $g_{0}$ is in $V_{0}^{k}(0)$, then $\left|g_{0}^{\prime \prime}(0)\right| \leqq$ $k$, so the result follows directly from Lemma 3 . This bound is sharp for the function $f(z)$ in $V_{\alpha}^{k}(\rho)$ defined by

$$
f^{\prime}(z)=\left\{\left[\frac{(1-z)^{(k-2) / 2}}{(1+z)^{(k+2) / 2}}\right]\right\}^{(1-\rho) e^{-i \alpha} \cos \alpha}
$$

LEMmA 5. If $f(z)$ is in $V_{\alpha}^{k}(\rho)$, then $F(z)$ defined by

$$
F^{\prime}(z)=\frac{f^{\prime}\left(\frac{z+a}{1+\bar{a} z}\right)}{f^{\prime}(a)(1+\bar{a} z)^{2(1-\rho) e^{-i \alpha^{\prime}} \cos \alpha}}, F(0)=0,|a|<1,|z|<1,
$$

is also in $V_{\alpha}^{k}(\rho)$.

Proof. By Lemma 2, for $f(z)$ in $V_{\alpha}^{k}(\rho)$, there exists $f_{0}(z)$ in $V_{0}^{k}(\rho)$ such that $f^{\prime}(z)=\left[f_{0}^{\prime}(z)\right]^{e^{-i x} \cos \alpha}$. By Lemma 3 in [9],

$$
\frac{f_{0}^{\prime}\left(\frac{z+a}{1+\bar{a} z}\right)}{f_{0}^{\prime}(a)(1+\bar{a} z)^{2(1-\rho)}} \text { is the derivative of }
$$

a function in $V_{0}^{k}(\rho)$. Hence

$$
\left[\frac{f_{0}^{\prime}\left(\frac{z+a}{1+\bar{a} z}\right)}{f_{0}^{\prime}(a)(1+\bar{a} z)^{2(1-\rho)}}\right]^{e^{-i \alpha} \cos \alpha}=\frac{f^{\prime}\left(\frac{z+a}{1+\bar{a} z}\right)}{f^{\prime}(a)(1+\bar{a} z)^{2(1-\rho) e^{-i \alpha} \cos \alpha}}
$$


is the derivative of a function in $V_{\alpha}^{k}(\rho)$.

THEOREM 3. If $f(z)$ is in $V_{\alpha}^{k}(\rho)$ and $0<k(1-\rho) \cos \alpha \leqq 1$, then $f(z)$ is univalent in $|z|<1$.

Proof. By the previous lemma, if $f(z)$ is in $V_{\alpha}^{k}(\rho)$, then $F(z)$ defined by

$$
F^{\prime}(z)=\frac{f^{\prime}\left(\frac{z+a}{1+\bar{a} z}\right)}{f^{\prime}(a)(1+\bar{a} z)^{2(1-\rho) e^{-i \alpha} \cos \alpha}}, \quad F(0)=0,
$$

is in $V_{\alpha}^{k}(\rho)$ also, with $|a|<1$ and $|z|<1$. Then

$$
\begin{aligned}
F^{\prime \prime}(z)= & {\left[(1+a z)^{2(1-\rho) e^{-i \alpha} \cos \alpha} f^{\prime \prime}\left(\frac{z+a}{1+\bar{a} z}\right) \cdot \frac{1-|a|^{2}}{(1+\bar{a} z)^{2}}\right.} \\
& \left.-2(1-\rho) e^{-i \alpha} \cos \alpha(1+\bar{a} z)^{2(1-\rho) e^{-i \alpha} \cos \alpha-1} \bar{a} f^{\prime}\left(\frac{z+a}{1+\bar{a} z}\right)\right] \\
& \times\left[f^{\prime}(a)(1+\bar{a} z)^{4(1-\rho) e^{-i \alpha} \cos \alpha}\right]^{-1}, \\
F^{\prime \prime}(0) & =\frac{f^{\prime \prime}(a)}{f^{\prime}(a)}\left(1-|a|^{2}\right)-2(1-\rho) e^{-i \alpha} \cos \alpha \bar{a} .
\end{aligned}
$$

Replacing $a$ by $z$, using Corollary 1 of Theorem 2, and multiplying through by $|z|$, we have

$$
\begin{aligned}
\mid \frac{z f^{\prime \prime}(z)}{f^{\prime}(z)} & \left(1-|z|^{2}\right)-2(1-\rho) e^{-i \alpha} \cos \alpha|z|^{2} \mid \\
& \leqq k(1-\rho) \cos \alpha|z|<k(1-\rho) \cos \alpha .
\end{aligned}
$$

Ahlfors' univalence criterion [1], with $c=2(1-\rho) e^{-i \alpha} \cos \alpha$, shows that $f$ is univalent in $E$ when $0<k(1-\rho) \cos \alpha \leqq 1$.

CoRollary 1. If $f(z)$ is in $V_{\alpha}^{k}(0), f$ is univalent in $E$ whenever

$$
0<\cos \alpha \leqq 1 / k
$$

This simplifies and improves bounds previously published for this class [7].

Corollary 2. If $f(z)$ is in $V_{0}^{k}(\rho)$, then $f$ is univalent in $E$ for

$$
\rho \geqq \frac{k-1}{k}
$$


Previously, it was shown in [9] that $f$ is univalent for $\rho \geqq$ $(k+1) /(k+2)$.

CoRollary 3. If $f(z)$ is in $V_{\alpha}^{2}(\rho)$, then $f(z)$ is univalent in $E$ when $0<\cos \alpha \leqq 1 / 2(1-\rho)$. $f$ need not be univalent if $\cos \alpha>1 /$ $[2(1-\rho)]$.

Chichra [4] has shown that for each $\alpha, 1 /[2(1-\rho)]<\cos \alpha<1$, there exists a function $f(z)$ in $F_{\alpha}^{\rho}=V_{\alpha}^{2}(\rho)$ such that $f(z)$ is not univalent in $E$. Hence the problem of univalence in $V_{\alpha}^{2}(\rho)$ is solved.

3. We may use the same function $f$ as in [4] to study conditions on $k, \alpha$, and $\rho$ which will allow functions in $V_{\alpha}^{k}(\rho)$ to be nonunivalent. Let

$$
g(z)=\frac{1}{\mu}\left[(1-z)^{-\mu}-1\right],
$$

and note

$$
g^{\prime}(z)=\frac{1}{(1-z)} \mu+1
$$

$g^{\prime}(z)$ has the form given in Theorem 2C, with $L_{1}^{\prime}(z)=(1-z)^{-1}$ and $L_{2}^{\prime}(z)=1$ and

$$
\mu+1=e^{-i \alpha} \cos \alpha(1-\rho)(k+2) / 4 .
$$

Hence $g(z)$ is in $V_{\alpha}^{k}(\rho)$ and, from an earlier result due to Royster [11], will not be univalent in $|z|<1$ when $|\mu+1|>1$ and $|\mu-1|$ $>1$. The first condition requires that

$$
\cos \alpha(1-\rho)(k+2) / 4>1,
$$

while the second condition simplifies to

$$
\cos ^{2} \alpha(1-\rho)(k+2)\left[\frac{(1-\rho)(k+2)}{16}-1\right]>-3 .
$$

We may use these conditions to analyze the nonunivalence of functions in subclasses of $V_{\alpha}^{k}(\rho)$ which have been previously studied. When $\rho=0$, the conditions defined by (2.1), (3.3) and (3.4) appear in Fig. 1. All functions in $V_{\alpha}^{k}(0)$ with $k$ and $\alpha$ corresponding to points in region 1 are univalent, by (2.1). In region $3,(k+2) \cos \alpha /$ $4>1$ and condition (3.4) is satisfied for all $k>6$ when $0<\cos \alpha$ $<\sqrt{3 / 2} ;$ for $\sqrt{3 / 2} \leqq \cos \alpha<1, \quad$ (3.4) is equivalent to $k>6-4[4$ $\left.\cos ^{2} \alpha-3\right]^{1 / 2} / \cos \alpha$. When $g(z)$ defined by (3.1) is chosen so as to correspond with points in region 3 , it will not be univalent. When 


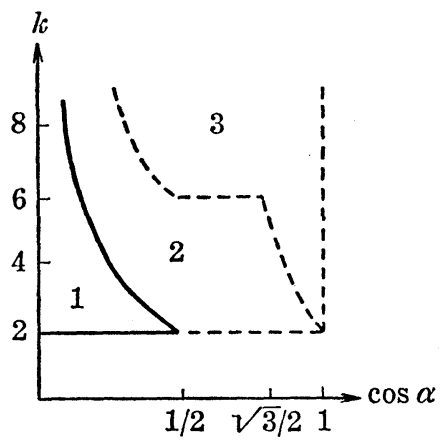

Figure 1

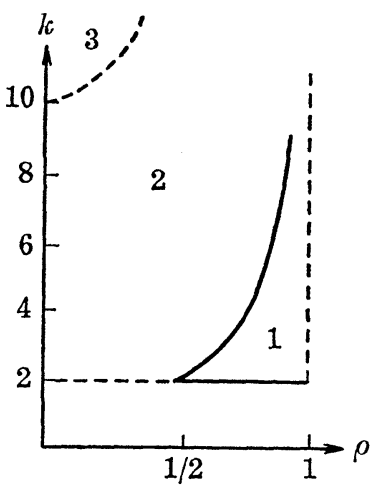

Figure 2

$k$ and $\alpha$ correspond to points in region 2 , it is an open question whether such $f$ in $V_{r}^{k}(0)$ will be univalent.

Fig. 2 is the corresponding diagram for univalence in the class $V_{0}^{k}(\rho)$. Region 1 depicts inequality (2.2), and all functions $g$ defined by (3.1) with $k, \rho$ satisfying (3.2) for $\alpha=0$ are univalent in $|z|<1$. Conditions (3.3) and (3.4) require that $\rho<(k-10) /(k+2)$, and for these values of $\rho$ and $k$ (in region 3), $g(z)$ will not be univalent. Region 2 shows those values of $k$ and $\rho$ for which the univalency of functions in $V_{0}^{k}(\rho)$ is an open question. We note that when $k=2$, the equation (3.1) defines the function used by Chichra in showing that there exist functions $f$ in $F_{\alpha}^{o}=V_{\alpha}^{2}(\rho)$ where $f$ is not univalent in $|z|<1$, for $1 / 2(1-\rho)<\cos \alpha<1$.

\section{REFERENCES}

1. L. V. Ahlfors, Sufficient conditions for quasi-conformal extensions, Annals of Mathematics Studies 79, Princeton, N.J., 1974.

2. S. K. Bajpai and T. J. S. Mehrok, On the coefficient structure and a growth theorem for the functions $f(z)$ for which $z f^{\prime}(z)$ is spirallike, Publ. Inst. Math. (Beograd.) N. S., 16 (30), 1973, 5-12. 
3. D. A. Brannan, On functions of bounded boundary rotation I, Proc. Edinburgh Math. Soc., 16 (1968), 339-347.

4. P. N. Chichra, Regular functions $f(z)$ for which $z f^{\prime}(z)$ is $\alpha$-spirallike, Proc. Am. Math. Soc., 49 \#1, 1975, 151-160.

5. Prem K. Kulshrestha, Bounded Robertson functions, Rend. Mat., (6)9 (1976), no. $1,137-150$.

6. R. J. Libera and M. R. Ziegler, Regular functions $f(z)$ for which $z f^{\prime}(z)$ is $\alpha$-spiral, Trans. Amer. Math. Soc., 166 (1972), 361-370.

7. E. J. Moulis, A generalization of univalent functions with bounded boundary rotation, Trans. Am. Math. Soc., 174 (1972), 369-381.

8. V. Paatero, Uber die konforme Abbildung von Gebieten deren Ränder von beschränkter Drehung sind, Ann. Acad. Sci, Fenn. Ser. A (33) 9 (1931), 77

9. K. S. Padmanabhan and R. Parvatham, Properties of a class of functions with bounded boundary rotation, Ann. Polon. Math., 31, no. 3, (1975), 311-323.

10. M. S. Robertson, Univalent functions $f(z)$ for which $z f^{\prime}(z)$ is spirallike, Michigan Math. J., 16 (1969), 97-101.

11. W. C. Royster, On the univalence of a certain integral, Michigan Math. J., 12 (1965), 385-387.

12. P. I. Sizuk, Regular functions $f(z)$ for which $z f^{\prime}(z)$ is O-spiral shaped of order $\alpha$, Sibirsk. Mat. Z., 16 (1975), 1286-1290, 1371.

13. E. M. Silvia, A variational method on certain classes of functions, Rev. Roumaine Math. Pures Appl., 21 (1976), no. 5, 549-557.

Received March 14, 1978.

United States Naval Academy

ANNAPOLIS, MD 21402 


\section{PACIFIC JOURNAL OF MATHEMATICS}

EDITORS

DONALD BABBITT (Managing Editor)

University of California

Los Angeles, California 90024

HUGo RossI

University of Utah

Salt Lake City, UT 84112

C. C. MOORE

J. DUGUNDJI

Department of Mathematics

University of Southern California

Los Angeles, California 90007

R. FinN AND J. MiLgraM

Stanford University

Stanford, California 94305

University of California

Berkeley, CA 94720

\section{ASSOCIATE EDITORS}

E. F. BrCKENBACH

B. H. NeUmanN

F. WOLF

K. YoshidA

\section{SUPPORTING INSTITUTIONS}

UNIVERSITY OF BRITISH COLUMBIA

UNIVERSITY OF SOUTHERN CALIFORNIA

CALIFORNIA INSTITUTE OF TECHNOLOGY

STANFORD UNIVERSITY

UNIVERSITY OF CALIFORNIA

UNIVERSITY OF HAWAII

MONTANA STATE UNIVERSITY

UNIVERSITY OF TOKYO

UNIVERSITY OF NEVADA, RENO

UNIVERSITY OF UTAH

NEW MEXICO STATE UNIVERSITY

WASHINGTON STATE UNIVERSITY

OREGON STATE UNIVERSITY

UNIVERSITY OF WASHINGTON

UNIVERSITY OF OREGON 


\section{Pacific Journal of Mathematics}

\section{Vol. 81, No. $1 \quad$ November, 1979}

Thomas E. Armstrong, Simplicial subdivision of infinite-dimensional compact cubes ..................................... 1

Herbert Stanley Bear, Jr., Approximate identities and pointwise convergence ................................

Richard David Bourgin, Partial orderings for integral representations on convex sets with the Radon-Nikodým property..................

Alan Day, Herbert S. Gaskill and Werner Poguntke, Distributive lattices

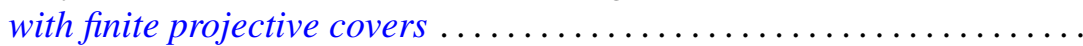

Heneri Amos Murima Dzinotyiweyi and Gerard L. G. Sleijpen, A note on measures on foundation semigroups with weakly compact orbits ......

Ronald James Evans, Resolution of sign ambiguities in Jacobi and Jacobsthal sums ...................................

John Albert Fridy, Tauberian theorems via block dominated matrices ......

Matthew Gould and Helen H. James, Automorphism groups retracting onto

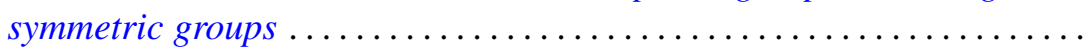

Kurt Kreith, Nonlinear differential equations with monotone solutions . . . . 101

Brian William McEnnis, Shifts on indefinite inner product spaces........ 113

Joseph B. Miles, On entire functions of infinite order with radially

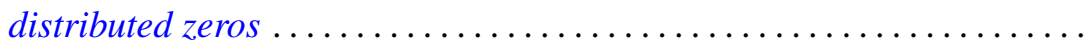

Janet E. Mills, The idempotents of a class of 0-simple inverse semigroups ...............................

Edward Jean Moulis, Jr., Generalizations of the Robertson functions ...

Richard A. Moynihan and Berthold Schweizer, Betweenness relations in probabilistic metric spaces.......................

Stanley Ocken, Perturbing embeddings in codimension two ....

Masilamani Sambandham, On the average number of real zeros of a class of random algebraic curves.

Jerry Searcy and B. Andreas Troesch, A cyclic inequality and a related eigenvalue problem.

Roger R. Smith and Joseph Dinneen Ward, $M$-ideals in $B\left(l_{p}\right)$...

Michel Talagrand, Deux généralisations d'un théorème de I. Namioka ..

Jürgen Voigt, $O n Y$-closed subspaces of $X$, for Banach spaces $X \subset Y$;

existence of alternating elements in subspaces of $C(J)$

Sidney Martin Webster, On mapping an $n$-ball into an $(n+1)$-ball in complex spaces

David J. Winter, Triangulable subalgebras of Lie p-algebras ... 